EESTI NSV TEADUSTE AKADEEMIA TOIMETISED. 20. KÖIDE

KEEMIA * GEOLOOGIA. 1971, NR. 3

ИЗВЕСТИЯ АКАДЕМИИ НАУК ЭСТОНСКОП ССР. ТОМ 20

Химия * ГЕОЛОГИя. 1971, № 3

\title{
О СВЯЗЯХ МЕЖДУ НЕОТЕКТОНИЧЕСКИМИ И СОВРЕМЕННЫМИ ДИФФЕРЕНЦИРОВАННЫМИ ДВИЖЕНИЯМИ И ЗОНАМИ РАЗЛОМОВ В СЕВЕРО-ВОСТОЧНОЙ ЭСТОНИИ
}

В последние два десятилетия тектоническому строению и тектоническим движениям южного склона Балтийского щита уделено много внимания. Одним из наиболее изученных районов является Северная Эстония, особенно ее восточная часть. Здесь получены данные о структуре кристаллического фундамента и распространении разломов, указывающие на его мелкоблоковое строение (Побул, 1962; Maasik, 1961 и др.). В осадочном чехле Северо-Восточной Эстонии выявлены и охарактеризованы некоторые сбросы и флексуры северо-восточного простирания, а также группа брахискладок в районе Ульясте (Вахер и др., 1962). В ряде работ рассматривается тектоническая трещиноватость палеозойских пород Прибалтийского сланцевого бассейна (Гатальский, 1959; Хейнсалу, 1962; Газизов, Янкович, 1965).

Ряд исследователей обращает внимание на то, что озы и озовые системы, приуроченные к трещинам в ледннке, следуют перегибам и зонам трещиноватости в коренных породах (Бискэ и др., 1959; Можаев, 1964; Лак, Лукашев, 1967; Берзин, 1969 и др.). Очевидно, тектонические движения по этим перегибам и зонам, проявившиеся во время отступания ледника, обусловили образование трещин, по которым, в свою очередь, развились русла ледниковых вод и образовались озы. Результаты изучения озов Северной Эстонии (Ряхни, 1960, 1967 и др.) позволяют нам присоединиться к этим взглядам и рассматривать территории многих озсвых систем как неотектонически активные зоны.

По данным Э. Ряхни, озы в Северной Эстонии представляют обычно. узкие гряды с крутыми склонами, образующие цепи и системы длиной до нескольких десятков километров. Их образование связывается в основном с открытыми трещинами ледника. Направление озовых гряд іи систем северс-западное, северо-восточное или субмеридиональное, при этом азимуты их простирания, по нашим данным, чаще всего колеблются в пределах $325-355^{\circ}$ и $15-45^{\circ}$. Основные системы тектонических трещин в Северной Эстонии имеют также северо-западное или северовосточное простирание. Озы часто прослеживают древние долины или склоны возвышенностей, направление которых хорошо согласуется с основными системами тектонических трещин и показывает, в свою очередь, зависимость простирания озєв от тектонической трещиноватости. Иногда озовые гряды располагаются параллельно долинам, пересекают долины или находятся в районах с весьма ровной поверхностью коренных пород. Эти озы отражают, по-видимому, молодые зоны трещин илю 
относятся к той их группе, которая не имеет связи с зонами разломов. Дифференцированные неотектонические движения, которые имели место во время отступания ледника, происходили не всегда по древним зонам трєщин, а иногда вызывали образование новых зон. Нельзя считать, что каждый оз образовался на месте зоны трещин, однако крупные их системы, на наш взгляд, генетически связаны с развитием зон разломов в коренных породах.

На прямую связь между распространением озовых систем и зон трещиноватости показывает, в частности, приуроченность к озам многочисленных и часто водообильных трещино-карстовых источников. В ряде случаев эти источники дают начало рекам и участвуют непосред. ственно в питании озер. Местами на возвышенных участках рельефа около озовых гряд встречаются карстовые воронки, поглощающие весенние талые воды и ручьи. Карстовые явления в озовых системах наблюдаютея как около древних долин, так и в районах с ровной поверхностью коренных пород. В озовых системах известны и карстовые озерки (Мӓеmets, 1969).

В настоящее время весьма хорошо известен характер неотектонического поднятия территории Северной Эстонии в поздне- и послеледниковое время (Кессел, 1961; Раукас и др., 1965; Мийдел, 1966; Орвику, $1960,1969)$. Точным повторным нивелированием, проведенным в Инсти. туте физики и астрономии АН ЭССР (Желнин, 1964, 1965), здесь установлена скорость современного тектонического поднятия и выявлена ее неравномерность - резкое измененне скорости современного поднятия на многих участках трасс повторного нивелирования.

Для установления связи между неотектоническими и современными движениями и зонами разломов осадочного чехла и кристаллического фундамента Северо-Восточной Эстонии ниже приводится сопоставление соответствующих данных (см. рисунок). При этом учтены только те участки профилей нивелирования, где группы реперов имеют сравнительно одинаковые характер и тенденцию движения, а на стыках этих участков выявляются места дифференцированных движений.

По относительно повышенным граднентам силы тяжести, а также по магнитному полю в структуре кристаллического фундамента северозападной части рассматриваемой территории выделяется тапаский блок. Его ограничивают разломы, среди которых наиболее четко вырисовываєтся разлом по западной границе блока, и пересекают небольшие нарушения (Побул, 1962). Над средней и южной частями блока располагаются озовые гряды, вытянутые в основном вдоль границ блока. Особенно много озов над западной границей блока, где они имеют разные направления. На местах пересечения границ блока и систем озов с древними долинами встречаются группы больших карстовых источников и озер, питающихся карстовыми водами. Данные повторного нивелирования трасс, пересекающих разломы тапаского блока в нескольких местах, показывают, что участки резких изменений скорости вертикальных движений совпадают с границами блока, а в нескольких местах -.. с озами.

По гравитационному полю в северной части исследованной территории выделяется ульястеский блок. В осадочном чехле западную границу блока отмечает азериский сброс, по которому на некоторых участках развиты озы. Около оза Вылумяги находится участок резких изменений вертикальных движений.

В южной части ульястеского блока имеется ряд локальных интенсивных гравимагнитных аномалий. Здесь в некоторых местах кристаллического фундамента установлены небольшие поднятия, образующие 


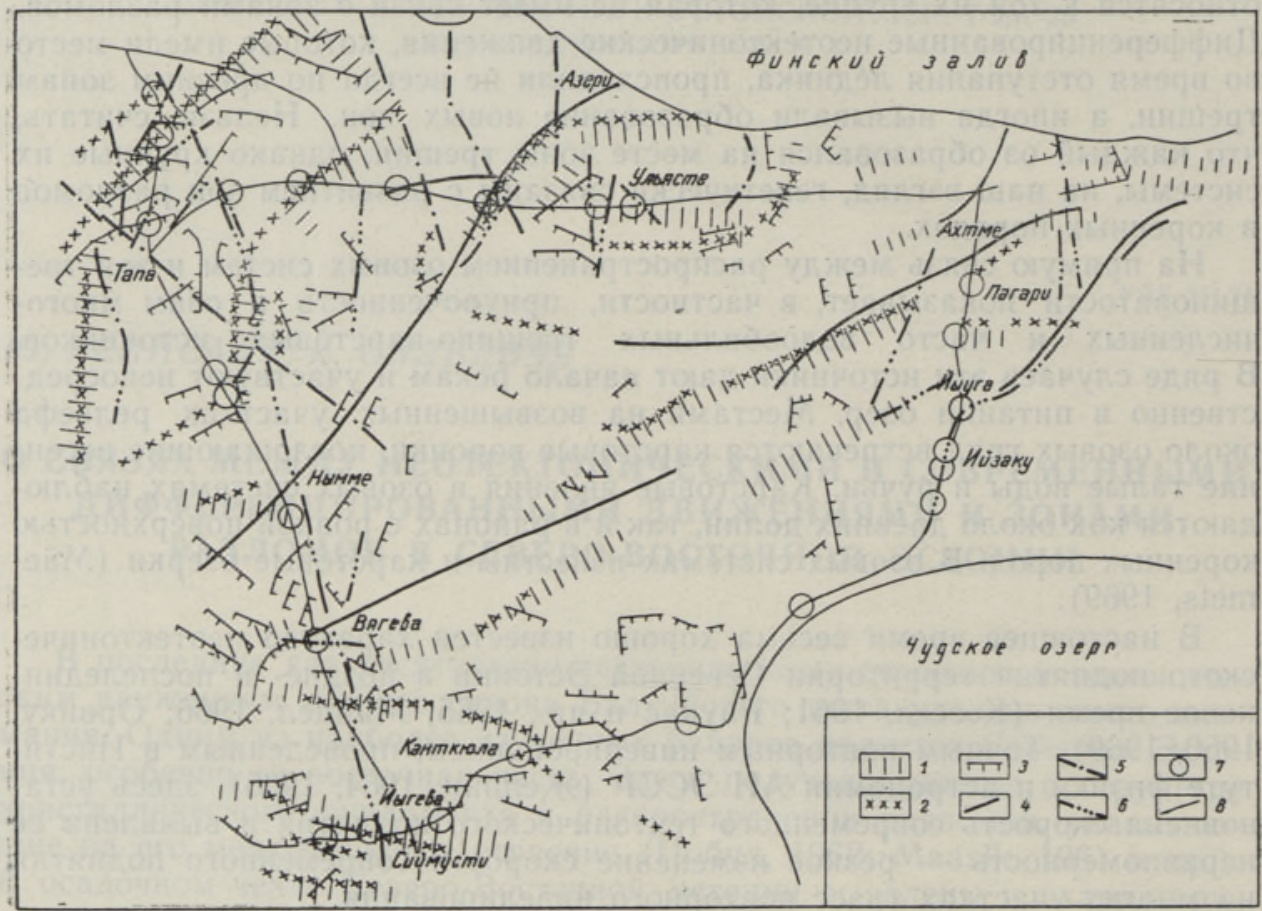

Схематическая карта сопоставления зон разломов кристаллического фундамента и осадочного чехла Северо-Восточной Эстонни.

$1-3$ - предполагаемые зоны разломов в кристаллическом фундаменте:

1 - по данным общего гравитационного поля в редукции Буге; 2 - по остаточным гравитационным аномалиям: 3 - по магнитыым данным; 4-6- зоны разломов в осадочном чехле: 4 - по данным бурения и электроразведки; 5 - по данным древних долин; 6 - по данным озовых систем. 7 - участки резкого изменения скоростей современных вертикальных движений. 8 - трасса повторного нивелирования.

в осадочном чехле куполовидные брахискладки (Вахер и др., 1962). В Ульясте находятся также озовые гряды субмерндионального и северозападного простираний, которые расположены в пределах зон градиентов гравиметрических и магнитных аномалий. К большой озовой гряде Ульясте приурочен ряд карстовых явлений в виде воронок и источников. Очевидно, на месте озовых гряд находятся зоны разломов, по которым происходили неотектонические движения. Около этих озов установлены также участки резких изменений современных тектонических движений.

Северо-Восточная Эстония пересекается зонами относительно повышенных градиентов силы тяжести северо-восточного простирания, показывающими, что на их месте проходят разломы в кристаллическом ффундаменте. По этим зонам градиентов развит ахтмеский сброс и субпараллельные ему локальные зоны трещин в осадочном чехле, во множестве выявленные между Финским заливом и Чудским озером. В этом районе в ряде случаев наблюдается согласованность между зонами разломов и участками, где выявлены дифференцированные движения. На месте ахтмеского сброса, как было отмечено уже Л. Уттером (1964), наблюдается резкое увеличение скорости вертикальных движений. Южнее ахтмеского сброса, около пос. Пагари и д. Ридакюла, выявленные участки резкого изменения скоростей вертикальных движений совпадают с градиентами локальных аномалий силы тяжести. Четыре отрезка резкого изменения вертикальных движений, установленных $\mathrm{s}$ окрестностях пос. Йыуга и Ийзаку (см. рисунок), совпадают с вийви- 
ксннаской зоной нарушения. Вдоль этого нарушения, на участке Иллука-Ийзаку, вытянута система озов, которая свидетельствует о неотектонической активности этой зоны.

Рассматриваемая территория ограничена с юга региональной зоной разломов широтного простирания в кристаллическом фундаменте (Побул, 1962; Головин, 1966 и др.). Установленные в пределах этой зоны участки дифференцированных вертикальных движений приурочены в основном к ее краям. На северной границе зоны разломов, в окрестности д. Канткюла, находится один участок аномальных вертикальных движений. На южной границе зоны, в районе г. Ныгева, установлено три участка резких изменений скоростей вертикальных движений, совпадающих с зоной относительно повышенных градиентов силы тяжести и градиентами магнитных аномалий. При этом западный участок пересекается озовой грядой Сиймусти, которая является южной частью озовой системы Сиймусти-Эбавере. Последняя, имея субмеридиональное простирание и протяженность более 40 км, отмечает, по-видимому, региональную неотектоническую зону разломов.

В районе между тапаским блоком и региональной зоной разломов широтного простирания находится ряд локальных геофизических и геологических структур, имеющих разное простирание. Здесь, в окрестностях пос. Вягева и Нымме, обнаруживается хорошее совпадение участков дифференцированных тектонических движений и зон разломов, выделенных по геофизическим и геологическим данным. Локальные зоны разломов этого района, отмеченные озами, имеют более прерывистый характер и неустойчивое направление, согласуясь в этом отношении со структурным строением кристаллического фундамента. С ними связаны крупные карстовые источники и озерки в окрестностях местечка Янту и других местах.

Сравнение показывает, что из 25 участков резкой смены скоростей вертикальных движений с местами разломов в кристаллическом фундаменте совпадает около $70-80 \%$, а с озами около $60 \%$. Таким образом, современные дифференцированные и неотектонические движения и структурное строение Северо-Восточной Эстонии, про всей видимости, взаимосвязаны. Эти движения происходят по зонам разломов, которыс являются границами блоков, по-видимому, разного порядка. Зоны разломов местами совпадают в осадочном чехле и кристаллическом фундаменте.

Из сказанного следует, что дифференцированные неотектонические движения оказывали значительное влияние на образование флювиогляциальных потоков, а следовательно и на распространение их отложений и форм рельефа. Дальнейшее изучение этих движений и зон тектонических разломов комплексными методами представляет интерес не только с точки зрения тектоники, но и четвертичной геологин, геоморфологии и гидрогеологии.

\section{ЛИТЕ РАТ У РА}

Берзин Н Л. Э. 1969. Основные черты новейшей тектоники территории Латвийской ССР. Автореф. канд. дисс. М.

Би скэ Г. С., Крац К. С. и Каз а ков а С. И. 1959. Опыт анализа взаимосвязи между тектоникой, рельефом и типом урочищ Карелин, Уч. зап. Латвийск. ун-та, 31.

Вахер Р. М., Пуура В. А. и Эрисалу Э. К. 1962. Тектоническое строение Северо-Восточной Эстонии. Тр. Ин-га геол. АН ЭССР, $\mathbf{x}$.

Г аз изов М. С., Янкович М. С. 1965. Трещиноватость горных пород ордовика и ее роль при разработке сланцевых месторождений Прибалтики. В сб.: Специальные вопросы стронтельства шахт и карьеров. Научн, сообщ. Ин-та горного дела им. А. А. Скочинского, XXVII. М. 
Г а т а льски й М. А. 1959. Микродислокация и трещиноватость пород в районе Прибалтики и их значение в миграции и распределении флюидов. Тр. ВНИГРИ, Геол. сб., 4, вып. 131. Л.

Головин И. А. 1966. К вопросу о связи современных движений земной коры с геофизическими аномалиями на северо-западе Русской платформы. В сб.: Вопр. разведочной геофиз., вып. 5.

Желнин Г. А. 1964. Точность и возможности метода повторного нивелирования. В сб.: Современные и новейшие движения земной коры в Прибалтике. Вильнюс, Желнин Г. А. 1965. О колебательном характере современных движений земной коры в Эстонской ССР. В сб.: Современные движения земной коры, 2. Тарту.

Кессел Х. Я. 1961. Древние береговые образования бассейна Балтийского моря в Эстонской ССР. Тр. Ин-та геол. АН ЭССР, VIII.

Л а к Г. Ц., Л у к а ше в А. Д. 1967. Неотектоника в зоне докембрийских разломоБ Южной Карелил. В сб.: Тектонические движения и новейшие структуры земной коры.

Мийдел А. М. 1966. О связи между современными движениями земной коры и эрозионно-аккумулятивной деятельностью рек Эстонии. Изв. АН ЭССР, Сер. физ.-матем. и техн. н., № 1.

Мож а е в Б. Н. 1964. О связи флювиогляцнальных форм рельефа области Валдайского оледенения с рельефом ледникового ложа. Тезисы докл. и кратких сообщ. 2-го межведомств. совещ. по изученню краевых образований материкового оледенения. Минск.

О рвику К. К. 1960. О неотектонических движениях в Эстонской ССР на основе геологических данных. В сб.: Неотектонические движения в Прибалтике. Тарту.

О р в и ку К. К. 1969. Влияние поднятия земной коры на геолого-геоморфологическое развитие территории Эстонии в позднеледниковое время и в голоцене. В сб.: Новейшие движения, вулканизм и землетрясение матеріков и дна океанов. М.

Побул Э. А. 1962. О строении кристаллического фундамента Эстонии по данным геофизики. Тр. Ин-та геол. АН ЭССР, Х.

Р аука с А. В., Кессел Х. Я., Эльтерм ан Г. Ю. 1965. Строение древних аккумулятивных береговых форм в Эстонии. В сб.: Литология и стратиграфия четвертичных отложений в Эстонии. Таллин.

Р я хни Э. Э. 1960. О генезисе озов Северной Эстонии. Тр. Ин-та геол. АН ЭССР, V.

Ряхни Э. Э. 1967. Озы и краевые образования последнего оледенения на Пандивереской возвышенности (Эстонская ССР). Автореф. канд. дисс. Таллин.

У т тер Л. Р. 1964. Попытка геологической интерпретации схемы изобаз территории Эстонской ССР. В сб.: Современные и новейшие движения земной коры в Прибалтике. Вильнюс.

Хейнсалу Ю. И. 1962. К вопросу образования тектонической трещиноватости северо-восточного простирания в Эстонии. Тр. Ин-та геол. АН ЭССР, Х.

Ma a sik V. 1961. Kirde-Eesti aluskorra ja aluspōhja struktuuride detailne uurimine gravimeetrilise meetodiga. Eesti NSV TA Toimet., tehn. ja füüs.-mat. tead. seeria, Nr. 4.

$M$ ä e met s A. 1969. Eesti karstijärvedel. Eesti Loodus, Nr. 11.

Ннститут геологии

Академии наук Эстонской ССР
Поступила в редакцию $28 / 11971$

\section{U. HEINSALU, H. SILDVEE}

\section{NEOTEKTOONILISTE JA NUODISAEGSETE DIFERENTSEERITUD LIIKUMISTE SEOSEST ALUSKORRA JA PEALISKORRA RIKKEVOONDITEGA KIRDE-EESTIS}

Neotektooniliste ja nüüdisaegsete tektooniliste liikumiste ning aluskorra ja pealiskorra rikkevööndite omavahelise seose väljaselgitamiseks vőrreldi aluskorra ja pealiskorra struktuurielementide ning rikkevööndite ja nüüdisaegsete diferentseeritud liikumiste esinemiskohti, mis on avastatud geofüüsika ja geoloogia andmetel ning kordusloodimiste tulemusena. Rikkevööndite eristamisel lähtuti seisukohast, et vanad orud ja ooside süsteemid on tekkinud lōhevööndite kohal ning jälgivad neid. Neotektoonilised liikumised rikkevööndites pōhjustasid ulatuslike lôhede tekkimist mandrijääs piki rikkevööndeid, millede järgi kujunesid oosid. Analüüs näitab, et kordusloodimise trassidel paikneb 25-st kohast, kus on toimunud vertikaalsete liikumiste kiiruse järsk muutus $70-80 \%$ aluskorra rikkevööndite ning $60 \%$ ooside süsteemide kohal. Järelikult on neotektooniliste ja kaasaegsete diferentseeritud liikumiste ning vaadeldava ala struktuurilise ehituse vahel lähedane seos. Need liikumised toimuvad piki rikkevööndeid, mis eraldavad erinevat järku plokke. 
U. HEINSALU, H. SILDVEE

\section{DIE ABHÄNGIGKEIT DER NEOTEKTONISCHEN UND DER GEGENWARTIGEN DIFFERENZIERTEN BEWEGUNGEN IM NORDÖSTLICHEN ESTLAND VON DEN STÖRUNGSZONEN DES GRUNDGEBIRGES UND DER TAFELDECKE}

Zur Aufklärung der Abhängigkeit der neotektonischen und der gegenwärtigen tektonischen Bewegungen von den Störungszonen des Grundgebirges und der Tafeldecke sind die strukturellen Elemente in den betreffenden Zonen, sowie die differenzierten Bewegungen der Gegenwart verglichen worden. Dabei stützte man sich auf geophysikalische und geologische Angaben und auf die Ergebnisse wiederholter Nivellierungen. Ausgegangen wurde vom Standpunkt, daß die Urtäler und die Osersysteme über den Störungszonen liegen und dieselben verfolgen. Die neotektonischen Bewegungen in den Störungszonen bedingten die Entstehung ausgedehnter Klüfte des Festlandeises. Diese Klüfte entsprachen den Störungszonen; später bildeten sich hier die Oser. Auf den Trassen der wiederholten Nivellierungen ist festgestellt worden, daB von 25 Stellen, an denen die Geschwindigkeit der vertikalen Bewegungen eine scharfe Veränderung erfährt, $70-80 \%$ über den Störungszonen des Grundgebirges und $60 \%$ in der Nähe der Osersysteme liegen.

Es besteht also eine enge Verbindung zwischen den neotektonischen und den gegenwärtigen differenzierten Bewegungen einerseits und der Struktur der betrachteten Areale andererseits; diese Bewegungen verfolgen die Störungszonen. 